\title{
Structural Effect on the Oxygen Evolution Reaction in the Electrochemical Catalyst FePt
}

\author{
Wonseok JEOng · Gijae KAnG · Kyeyoup KIM · Gabin YoOn · Kisuk KAng · Seungwu HAN* \\ Department of Materials Science and Engineering, Seoul National University, Seoul 08826, Korea
}

(Received 9 June 2015 : revised 2 July 2015 : accepted 6 July 2015)

\begin{abstract}
We investigated the overpotential of the oxygen evolution reaction for the FePt catalyst by using a density functional theory calculation. We conducted the calculation for two types of FePt catalysts: FePt with an ordered $\mathrm{L}_{0}$ crystal structure and FePt with atoms randomly distributed at the face-centered-cubic (FCC) crystal sites. First, we investigated the surface energy of the $\mathrm{L} 1_{0} \mathrm{FePt}$ surface and concluded that the reacting surface was a (111) surface because of its low surface energy. Next, we calculated the free energy of the oxygen evolution reaction (OER) steps and obtained the theoretical overpotentials for the two types of FePt catalysts. The overpotentials for the ordered $\mathrm{L}_{0}$ and the disordered FCC FePt catalysts were found to be $2.26 \mathrm{~V}$ and $2.17 \mathrm{~V}$, respectively. The disordered FCC FePt is expected to have a higher catalyst activity than the ordered $\mathrm{L} 1_{0} \mathrm{FePt}$.
\end{abstract}

PACS numbers: 82.45.Jn, 31.15.A-, 88.30.E-

Keywords: FePt, Water splitting, Catalyst, Oxygen evolution reaction (OER), ab initio

\section{결정 구조가 $\mathrm{FePt}$ 산소 발생 반응 전기 화학적 촉매에 미치는 영향}

\author{
정원석 · 강기재 · 김계엽 · 윤갑인 · 강기석 · 한승우* \\ 서울대학교 재료공학부, 서울 08826
}

(2015년 6월 9일 받음, 2015년 7월 2일 수정본 받음, 2015년 7월 6일 게재 확정)

\begin{abstract}
제일원리 밀도범함수이론 계산을 통해 정렬된 $\mathrm{L} 1_{0}$ 결정구조의 $\mathrm{FePt}$ 와 $\mathrm{FCC}$ 구조에서 원자가 무 작위로 배치되어 있는 $\mathrm{FePt}$ 촉매의 산소 발생 반응 과전압을 알아보았다. 다양한 표면 방위에 대한 에너지 계산 결과, $\mathrm{L} 1_{0} \mathrm{FePt}$ 의 (111)면이 가장 안정하여 반응에 가장 크게 관여하는 표면임을 알 수 있었다. 산소 발생 반응의 각 단계의 자유 에너지를 계산하여 각 촉매의 이론적 과전압을 계산한 결 과, $\mathrm{L}_{0}$ 결정구조의 $\mathrm{FePt}$ 와 원자 배열이 무작위한 $\mathrm{FCC} \mathrm{FePt}$ 의 과전압은 각각 $2.26 \mathrm{~V}, 2.17 \mathrm{~V}$ 로 원 자 배열이 무작위한 $\mathrm{FCC} \mathrm{FePt}$ 의 과전압이 $0.09 \mathrm{~V}$ 낮게 계산되었다. 이는 산소 발생 반응 촉매로서 널리 쓰이는 $\mathrm{Pt}$ 의 과전압인 $2.55 \mathrm{~V}$ 보다 낮은 값이다.
\end{abstract}

PACS numbers: 82.45.Jn, 31.15.A-, 88.30.E-

Keywords: $\mathrm{FePt}$, 물 분해, 촉매, 산소 발생 반응, 제일 원리 계산

\footnotetext{
*E-mail: kensou3@snu.ac.kr
} (http://creativecommons.org/licenses/by-nc/3.0) which permits unrestricted non-commercial use, distribution, and reproduction in any medium, provided the original work is properly cited. 


\section{I. 서 론}

수소 가스를 이용한 수소 에너지는 탄소를 발생시키 지 않아 유력한 차세대 에너지원 후보로 각광받고 있다. 태양광을 이용한 전기화학적 물 분해는 수소 에너지의 연료인 수소 가스를 가장 환경친화적으로 얻는 방법으 로서 최근 많은 각광을 받고 있다.

일반적인 전기화학적 물분해 반응식은 다음과 같다 [1].

$$
2 \mathrm{H}_{2} \mathrm{O} \rightarrow \mathrm{O}_{2}+4 \mathrm{H}^{+}+4 e^{-}
$$

물의 전기화학적 분해는 산소 발생 반응 (Oxygen Evolution Reaction, OER)과 수소 발생 반응 (Hydrogen Evolution Reaction, HER)의 두 개의 반쪽 반응으로 이루어 져 있는데, 양극에서 수소 발생 반응이, 음극에서 산소 발생 반응이 일어난다.

$$
\begin{aligned}
& \text { Cathode }: 2 \mathrm{H}^{+}+2 e^{-} \rightarrow \mathrm{H}^{*}+\mathrm{H}^{+}+e^{-} \rightarrow \mathrm{H}_{2} \\
& \text { Anode }: 2 \mathrm{H}_{2} \mathrm{O} \rightarrow \mathrm{OH}^{*}+\mathrm{H}_{2} \mathrm{O}+e^{-}+\mathrm{H}^{+} \\
& \rightarrow \mathrm{O}^{*}+\mathrm{H}_{2} \mathrm{O}+2 e^{-}+2 \mathrm{H}^{+} \\
& \rightarrow \mathrm{OOH}^{*}+3 e^{-}+3 \mathrm{H}^{+} \\
& \rightarrow \mathrm{O}_{2}+4 e^{-}+4 \mathrm{H}^{+}
\end{aligned}
$$

표준상태에서 열역학적으로 계산한 산소 발생 반응의 전 압은 $1.23 \mathrm{~V}$ 이다. 그러나 실제 물분해 반응에서는 활성화 과전압 (activation overpotential), 농도 과전압 (concentration overpotential), 저항 과전압 (resistance overpotential) 등 여러 가지 원인에 의한 과전압 (overpotential, $\eta)$ 이 발생한다.

태양광 플럭스 $\left(10 \mathrm{~mA} / \mathrm{cm}^{2}\right)$ 하에서 과전압은 음극의 수소 발생 반응보다 양극의 산소 발생 반응에서 크게 발 생하는 것으로 알려져 있다 $[2,3]$. 따라서 적절한 촉매를 통해 산소 발생 반응의 과전압을 감소시켜 물분해에 필 요한 전압을 열역학적 최소전압인 $1.23 \mathrm{~V}$ 에 가깝게 낮출 필요가 있다.

물 분해 촉매로 흔히 사용되는 물질들은 $\mathrm{Pt}, \mathrm{TiO}_{2}, \mathrm{Co}$ 기반 물질, $\mathrm{Bi}$ 등이 있으며, 그중 $\mathrm{Pt}$ 는 높은 촉매 효율을 보여 예로부터 활발히 연구되고 있다. Pt는 산소 생성 반응의 반대 반응인 산소 환원 반응 (Oxygen Reduction Reaction, ORR)의 촉매로도 높은 효율을 보이는 것으로 알려져 있다. 그러나 희소 금속인 $\mathrm{Pt}$ 는 가격이 매우 비 싸며 제조 과정이 까다롭기 때문에, 연료 전지의 산소 환 원 반응 촉매로서는 순수한 $\mathrm{Pt}$ 금속보다 $\mathrm{Fe}, \mathrm{Co}, \mathrm{Ni}$ 등의
전이 금속과 결합한 합금이 더 많이 사용된다 [4,5]. 최근 들어 $\mathrm{Pt}$ 와 전이금속의 합금이 경제적 측면뿐 아니라 촉 매 효율 측면에서도 더 뛰어나다는 분석이 제시되고 있 으며, 그중 $\mathrm{Fe}$ 와 $\mathrm{Pt}$ 가 1 대 1 로 결합한 $\mathrm{FePt}$ 나노 입자의 경우 순수한 $\mathrm{Pt}$ 촉매보다 산소 환원 반응 활성도 $(\mathrm{ORR}$ activity)가 뛰어나다는 연구 결과들이 발표되었다 [6-8].

실험적으로 합성된 $\mathrm{FePt}$ 는 면심입방 $(\mathrm{FCC})$ 결정 구 조 (이하 $\mathrm{d}-\mathrm{FePt}$ ) 내에서 격자점에 $\mathrm{Fe}$ 와 $\mathrm{Pt}$ 원자가 무질 서하게 분포된 결정구조 상태를 이룬다. 합성된 $\mathrm{FePt}$ 에 $530{ }^{\circ} \mathrm{C}$ 이상의 열을 가하면 상전이가 일어나며, 원자 배 열이 무질서한 $\mathrm{FCC}$ 구조에서 $\mathrm{Fe}$ 원자 층과 $\mathrm{Pt}$ 원자 층 이 (100) 면과 (200) 면으로 번갈아 나타나는 체심정방 $(\mathrm{FCT})$ 구조 (이하 o-FePt)로 바뀌게 된다. 이러한 형태 의 구조를 $\mathrm{L} 1_{0}$ 구조라고 지칭한다 [9-11].

현재까지 산소 환원 반응 촉매로서 $\mathrm{FePt}$ 에 대한 연구 는 실험적, 이론적으로 많이 진행되었으나, 산소 생성 반 응의 촉매로서의 $\mathrm{FePt}$ 는 상대적으로 연구가 미흡한 상 황이다. 따라서 본 연구에서는 $\mathrm{Pt}$ 와 $\mathrm{Fe}$ 가 1 대 1 로 결합 한 $\mathrm{FePt}$ 촉매에서의 산소 발생 반응을 이론적으로 분석 했다. $\mathrm{FePt}$ 의 산소 환원 반응 촉매로서의 역할을 분석한 연구에서는 무질서한 $\mathrm{FCC}$ 구조의 $\mathrm{d}-\mathrm{FePt}$ 보다 $\mathrm{L} 1_{0}$ 구조 의 $\mathrm{o}-\mathrm{FePt}$ 의 촉매 효율이 더 뛰어나다는 결과가 보고된 바 있다 [7]. 이에 이번 연구에서는 o-FePt와 d-FePt에 대해 밀도범함수이론 (Density Functional Theory) 계산 을 수행하여 $\mathrm{FePt}$ 의 구조가 촉매 효율에 미치는 영향을 알아보았다.

\section{II. 계산 방법}

모든 밀도범함수이론 계산은 EDISON 사업 중앙센터 에서 제공하는 Linear Combination of Atomic Orbitals 기반 Density Functional Theory 전자구조계산 SW과 [12] VASP (Vienna Ab initio Simulation Package) [13] 코드를 통해 계산을 수행하였다. 일반화된 기울기 근사 법 (Generalized Gradient Approximations, GGA) [16]을 이용한 PAW 유사 퍼텐셜 (Projector-augmented Wave Pseudopotential) 방법을 사용하였다 $[14,15]$. 표면 모델 링은 총 8 개의 $\mathrm{FePt}$ 층으로 이루어진 슬랩을 사용했으 며, 진공 슬랩을 $15 \AA$ 로 설정하여 주기경계조건 (Periodic Boundary Condition)에 의한 슈퍼셀 간의 상호작 용이 최소화되도록 했다. 평면파 전개를 위한 에너지 한 계치로 순수한 $\mathrm{FePt}$ 구조는 $300 \mathrm{eV}$ 를, 반응물과 결합한 구조는 $400 \mathrm{eV}$ 를 사용하였으며, 역격자 공간에서의 $\mathbf{k}$ point 샘플링은 $\Gamma$ 포인트를 사용하였다. o- FePt의 슬랩 
Table 1. Surface energy and surface energy per fomular unit of d-FePt with different surface coordinates.

\begin{tabular}{ccc}
\hline \hline Orientation & $\begin{array}{c}\text { Slab Energy } \\
{[\mathrm{eV} / \text { fomular unit }]}\end{array}$ & $\begin{array}{c}\text { Surface Energy } \\
{\left[\mathrm{meV} / \AA^{2}\right]}\end{array}$ \\
\hline$(100)$ & -12.02 & 32.80 \\
$(110)$ & -11.83 & 42.41 \\
$(111)$ & -12.09 & 26.98 \\
\hline \hline
\end{tabular}

은 알려진 $\mathrm{L}_{0}$ 구조의 $\mathrm{FePt}$ 슬랩에 격자 구조와 원자 구 조를 최적화시켜 얻었다. 최적화된 구조의 격자 상수 $\mathrm{a}$ 는 $3.91 \AA$ 이며 격자 상수 $\mathrm{c}$ 는 $3.74 \AA$ 으로 $\mathrm{c} / \mathrm{a}$ 비율은 0.95 이 다 [17]. d-FePt 슬랩을 만들 때 알려진 격자 상수 $3.84 \AA$ 를 갖는 $\mathrm{FCC}$ 구조의 슬랩을 형성한 후 난수 생성을 통 해 각 격자 점에 $\mathrm{Fe}$ 원자와 $\mathrm{Pt}$ 원자를 무작위로 배치하 였다 [18]. 이때 원자들의 전체 비율이 1 대 1 이 되도록 했 다. 계산에 사용된 모든 구조의 최적화는 각 원자가 받는 힘이 $0.02 \mathrm{eV} / \AA$ 이하가 되도록 하였다. W. H. Butler 등 의 연구 결과에 따르면 강자성 상호작용 (Ferromagnetic Coupling)을 이룬 FePt가 에너지적으로 가장 안정한 것 으로 알려져 있다 [19]. 따라서 이 연구에서는 모든 스 핀의 방향이 (001) 면에 수직인 방향으로 정렬한 강자성 형태의 스핀 배열에 대해 계산을 수행하였다.

\section{III. 결과 및 토의}

산소 발생 반응에 가장 크게 관여하는 o-FePt의 표면 방위를 알기 위해 o-FePt 표면의 방위에 따른 표면 에너 지를 다음과 같이 계산한다.

$$
\gamma=\frac{E_{\text {slab }}-E_{\text {bulk }}}{2 A}
$$

$\mathrm{E}_{s l a b}$ 과 $\mathrm{E}_{b u l k}$ 는 각각 슬랩과 벌크의 에너지를 나타내 며 $A$ 는 표면적을 뜻한다. 각 방위에 따른 표면 구조는 Fig. 1과 같으며, 각 구조의 표면 에너지와 원자 당 표면 에너지를 Table 1에 나타내었다.

계산 결과 (111) 면이 가장 낮은 표면 에너지를 가짐 을 알 수 있으며, 이하의 계산에서는 (111) 면을 지정하 여 계산을 수행하였다. o- FePt와 d-FePt의 격자 구조는 Fig. 2에 나타내었다. o-FePt는 (111)면을 표면 방위로 가 지는 체심정방 $(\mathrm{FCT})$ 격자 구조를 가지고 있다.

물 분해 반응에서 산소 발생 반응은 여러 단계에 걸쳐 일어나는데. 각 단계에 해당하는 반응식은 다음과 같다.

$$
\begin{aligned}
2 \mathrm{H}_{2} \mathrm{O}+* & \rightarrow \mathrm{OH}^{*}+\mathrm{H}_{2} \mathrm{O}+e^{-}+\mathrm{H}^{+} \\
\mathrm{OH}^{*}+\mathrm{H}_{2} \mathrm{O} & \rightarrow \mathrm{O}^{*}+\mathrm{H}_{2} \mathrm{O}+e^{-}+\mathrm{H}^{+} \\
\mathrm{O}^{*}+\mathrm{H}_{2} \mathrm{O} & \rightarrow \mathrm{OOH}^{*}+e^{-}+\mathrm{H}^{+} \\
\mathrm{OOH}^{*} & \rightarrow \mathrm{O}_{2}+e^{-}+\mathrm{H}^{+}
\end{aligned}
$$
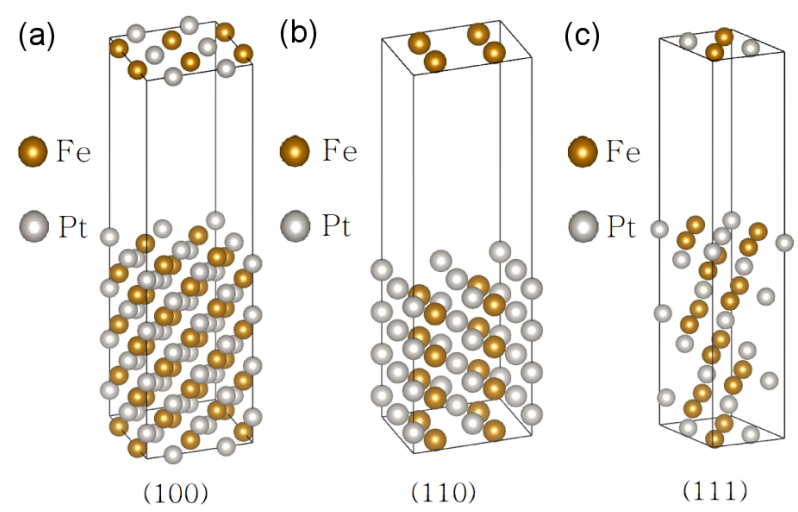

(110)

(111)

Fig. 1. (Color online) Lattice structure of o-FePt with (a) (100), (b) (110), (c) (111) surface coordinates.
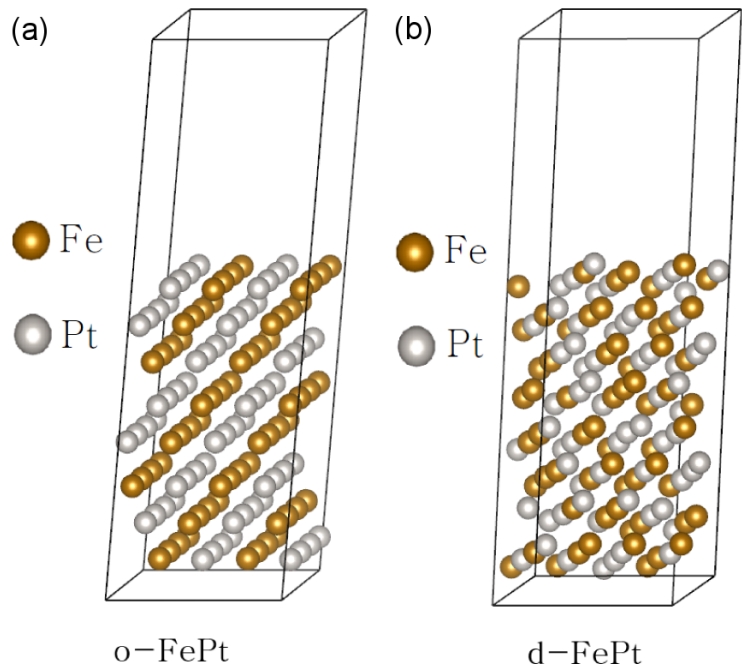

Fig. 2. (Color online) Lattice structure of (a) o-FePt and (b) d-FePt.

각 반응 단계의 자유 에너지는 다음과 같이 나타낼 수 있다 [20].

$$
\begin{aligned}
& \Delta G 1=E\left(\mathrm{OH}^{*}\right)-E(*)-E\left(\mathrm{H}_{2} \mathrm{O}\right)+\frac{1}{2} E\left(\mathrm{H}_{2}\right)-e U(9) \\
& \Delta G 2=E\left(\mathrm{O}^{*}\right)-E\left(\mathrm{OH}^{*}\right)+\frac{1}{2} E\left(\mathrm{H}_{2}\right)-e U \\
& \Delta G 3=E\left(\mathrm{OOH}^{*}\right)-E\left(\mathrm{O}^{*}\right)-E\left(\mathrm{H}_{2} \mathrm{O}\right)+\frac{1}{2} E\left(\mathrm{H}_{2}\right)-e U
\end{aligned}
$$

$\left.\Delta G 4=E\left(\mathrm{O}_{2}\right)-E\left(\mathrm{OOH}^{*}\right)+E(*)+\frac{1}{2}\left(\mathrm{H}_{2}\right)\right]-e U$

$U$ 는 표준상태에서 정상 수소 전극 (Normal Hydrogen Electrode, NHE)에 대해 측정한 퍼텐셜이다. 식 (9)(12)의 합은 실험적으로 구할 수 있는 두 물 분자의 생성 자유에너지인 $4.92 \mathrm{eV}$ 의 음의 값으로 고정하였다. 이는 GGA-DFT 계산의 경우 분자간 결합 에너지를 과소평가 
Table 2. Free energy of reactant and product with o-FePt and d-FePt catalyst.

\begin{tabular}{ccccccc}
\hline \hline Free Energy $[\mathrm{eV}]$ & $*$ & $\mathrm{O}^{*}$ & $\mathrm{OH}^{*}$ & $\mathrm{OOH}^{*}$ & $\mathrm{H}_{2} \mathrm{O}^{2}$ & $\mathrm{H}_{2}$ \\
\hline o-FePt & -782.70 & -788.04 & -792.45 & -796.45 & -14.03 & -6.72 \\
$\mathrm{~d}-\mathrm{FePt}$ & -769.19 & -774.88 & -779.05 & -783.38 & -14.03 & -6.72 \\
\hline \hline
\end{tabular}

Table 3. Free energy of reaction steps in $0 \mathrm{~V}$ and $1.23 \mathrm{~V}$ when o-FePt catalyst is used $[\mathrm{eV}]$.

\begin{tabular}{ccccc}
\hline \hline Voltage & Step 1 & Step 2 & Step 3 & Step 4 \\
\hline $0 \mathrm{~V}$ & 0.92 & 1.05 & 2.26 & 0.70 \\
$1.23 \mathrm{~V}$ & -0.31 & -0.18 & 1.03 & -0.54 \\
\hline \hline
\end{tabular}

Table 4. Free energy of reaction steps in $0 \mathrm{~V}$ and $1.23 \mathrm{~V}$ when d-FePt catalyst is used $[\mathrm{eV}]$.

\begin{tabular}{ccccc}
\hline \hline Voltage & Step 1 & Step 2 & Step 3 & Step 4 \\
\hline $0 \mathrm{~V}$ & 0.80 & 0.81 & 2.17 & 1.14 \\
$1.23 \mathrm{~V}$ & -0.43 & -0.42 & 0.94 & -0.09 \\
\hline \hline
\end{tabular}

하는 경향이 있기 때문이다. 계산에서 $\mathrm{pH}$ 를 0 이라 가정 했으므로 $\mathrm{H}^{+}$와 관련된 자유에너지는 0 이다. 두 표면 구 조에 각각의 분자를 흡착시켜 자유 에너지를 계산하였 으며 (Table 2), $\mathrm{OH}^{*}$ 가 흡착된 배치를 대표적인 예로서 Fig. 3에 나타내었다. 계산된 자유 에너지와 알려져 있는 $\mathrm{H}_{2} \mathrm{O}, \mathrm{O}_{2}, \mathrm{e}^{-}$의 자유에너지값을 이용하여 각 단계를 계 산했으며, 그 결과를 Table 3 와 Table 4 에 나타내었다.

위 식에서 이론적으로 계산할 수 있는 과전압 값은 다 음과 같다.

$$
\eta=\max [\Delta G 1, \Delta G 2, \Delta G 3, \Delta G 4] / e-1.23[V]
$$

Table 3 와 Table 4 에서 $1.23 \mathrm{~V}$ 전압을 걸었을 때 3 단 계의 반응 에너지가 양수임을 확인할 수 있으며, 따라서 3 단계 반응의 반응 에너지를 0 으로 만드는 전압과 1.23 $\mathrm{V}$ 전압의 차가 과전압이다.

Fig. 4 는 각 구조의 반응 단계에 따른 자유에너지 변화 를 나타낸 것이다. Fig. 4 에서 확인할 수 있듯 o-FePt와 $\mathrm{d}-\mathrm{FePt}$ 촉매의 과전압은 각각 $2.26 \mathrm{~V}, 2.17 \mathrm{~V}$ 로 d-FePt가 $0.09 \mathrm{~V}$ 낮은 과전압을 보였다. 이는 Rossmeisl의 연구에 서 알려진 $\mathrm{Pt}$ 촉매의 산소 생성 반응 과전압 $2.55 \mathrm{~V}$ 보다 낮은 값으로, 산소 환원 반응뿐 아니라 산소 생성 반응 에서도 $\mathrm{FePt}$ 가 매우 높은 촉매 활성도를 가짐을 뜻한다 [1]. 또한 산소 환원 반응 (ORR)에서 o-FePt가 d-FePt 보다 더 높은 촉매 효율을 보인 것에 반해, 산소 생성 반 응에서는 $\mathrm{d}-\mathrm{FePt}$ 의 촉매 효율이 더 높음을 알 수 있다. 따라서 $\mathrm{FePt}$ 나노입자를 산소 생성 반응 촉매로써 사용 할 경우 별도의 열처리 공정이 없이도 높은 촉매 효율을 기대할 수 있을 것으로 예상된다. (a)

- $\mathrm{H}$
- $\mathrm{O}$
- $\mathrm{Fe}$
O $\mathrm{Pt}$

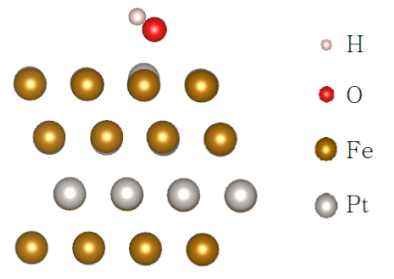

(b)

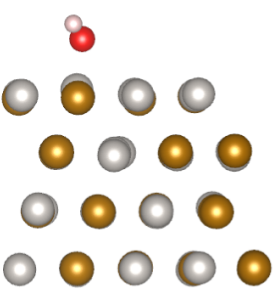

Fig. 3. (Color online) $\mathrm{OH}^{-}$molecule's position on the surface of (a) o-FePt and (b) d-FePt during OER.
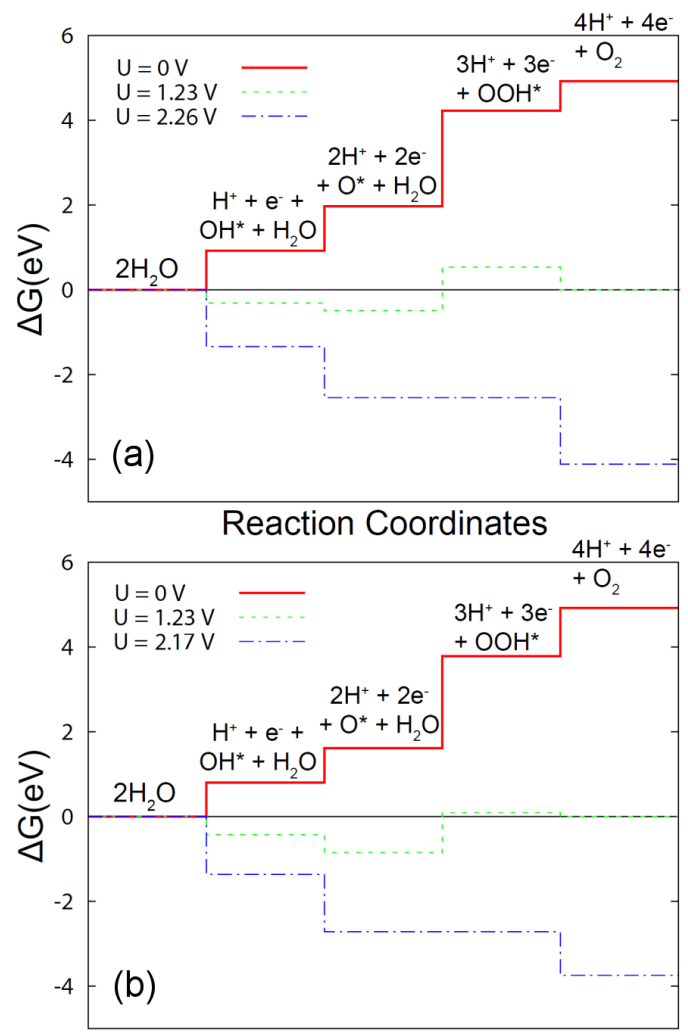

Reaction Coordinates

Fig. 4. (Color online) Free energy variation through OER with (a) o-FePt and (b) d-FePt catalyst.

\section{IV. 결 론}

일반화된 기울기 근사법 (GGA)을 사용한 밀도범함 수이론을 통해 정렬된 $\mathrm{L}_{0}$ 구조의 o-FePt와 $\mathrm{FCC}$ 구조 에서 원자의 배열이 무작위한 d-FePt의 산소 발생 반응 의 과전압을 알아보았다. 화학 반응에 관여하는 정렬된 
$\mathrm{o}-\mathrm{FePt}$ 의 표면 방위는 표면 에너지가 가장 낮은 방위인 (111) 면으로 계산하였다. 과전압 측정 결과 o-FePt와 d$\mathrm{FePt}$ 의 과전압은 각각 $2.26 \mathrm{~V}, 2.17 \mathrm{~V}$ 이었다. 산소 환원 반응과 달리 산소 생성 반응에서는 $\mathrm{d}-\mathrm{FePt}$ 의 촉매 효율 이 더 높은 것으로 나타났다. 이 연구는 $\mathrm{Pt}$ 와 전이금속 합금이 보다 저렴하고 높은 활성도의 산소 생성 반응 촉 매로 적용 가능함을 보였다.

\section{감사의 글}

본 논문은 2015 년도 정부 (미래창조과학부)의 재원으 로 한국연구재단 첨단 사이언스·교육 허브 개발 사업의 지원을 받아 수행된 연구입니다 (No. NRF-2012-M3C1A 6035302).

\section{REFERENCES}

[1] J. Rossmeisl, A. Logadottir and J. K. Nørskov, Chem. Phys. 319, 178 (2005).

[2] M. G. Walter, E. L. Warren, J. R. McKone, S. W. Boettcher and Q. Mi et al., Chem. Rev. 110, 6446 (2010).

[3] T. R. Cook, D. K. Dogutan, S. Y. Reece, Y. Surendranath and T. S. Teets et al., Chem. Rev. 110, 6474 (2010).

[4] J. Greeley, I. E. L. Stephens, A. S. Bondarenko, T. P. Johansson and H. A. Hansen et al., Nat. Chem. 1, 552 (2009).

[5] E. Antolini, J. R. C. Salgado and E. R. Gonzalez, Sci. Dir. 160, 957 (2006).
[6] S. Guo and S. Sun, J. Am. Chem. Soc. 134, 2492 (2012).

[7] J. Kim, Y. Lee and S. Sun, J. Am. Chem. Soc. 132, 4996 (2010).

[8] V. Mazumder, M. Chi, K. L. More and S. Sun, J. Am. Chem. Soc. 132, 7848 (2010).

[9] C. Rong, D. Li, V. Nandwana, N. Poudyal and Y. Ding et al., Adv. Mater. 18, 2984 (2006).

[10] R. A. Ristau, K. Barmak, L. H. Lewis, K. R. Coffey and J. K. Howard, J. Appl. Phys. 86, 4527 (1997).

[11] Z. R. Dai, S. Sun and Z. L. Wang, Nano Lett. 1, 443 (2001).

[12] http://nano.edison.re.kr (accessed June 4, 2015).

[13] G. Kresse and J. Furthmuller, Comput. Mater. Sci. 6, 15 (1996).

[14] P. E. Blochl, Phys. Rev. B 50, 17953 (1994).

[15] G. Kresse and D. Joubert, Phys. Rev. B 59, 1758 (1999).

[16] J. P. Perdew, K. Burke and M. Ernzerhof, Phys. Rev. Lett. 77, 3865 (1996).

[17] T. J. Klemmer, N. Shukla, C. Liu, X. W. Wu and E. B. Svedberg, Appl. Phys. Lett. 81, 2220 (2002).

[18] M. S. Seehra, V. Singh, P. Dutta, S. Neeleshwar, Y. Y. Chen et al., Appl. Phys. 43, 145002 (2010).

[19] Z. Lu, R. V. Chepulskii and W. H. Butler, Phys. Rev. B 81, 094437 (2010).

[20] M. Bajdich, M. Garcia-Mota, A. Vojvodic, J. K. Nørskov and A. T. Bell, J. Am. Chem. Soc. 135, 13521 (2013). 